\title{
DETERMINATION OF SHEAR MODULUS OF SOIL IN THE RC / TS APPARATUS FOR DESIGNING OFFSHORE WIND POWER PLANT FOUNDATIONS
}

\author{
Piotr Srokosz \\ Ireneusz Dyka \\ Marcin Bujko \\ The University of Warmia and Mazury in Olsztyn, Poland
}

\begin{abstract}
The paper presents a selected aspect of the determining the initial soil shear modulus value on the research example in resonant column - torsional shear apparatus (RC / TS). There are presented the significance of the initial value of shear modulus in design of offshore wind power plant foundations and the importance of its variability in the function of cyclical shear strains of soil related to the impact of sea and atmosphere on the designed structures. Based on the conducted analyses, a new methodology for interpreting the TS test results of soil has been proposed. It allows estimating the values of the shear modulus in the full range of shear strains occurring in issues closely related to the design and construction work of offshore wind power plant foundations.
\end{abstract}

Keywords: offshore wind power, shear modulus, back analysis, numerical modelling

\section{INTRODUCTION}

Problems associated with the depletion of raw materials used for energy production motivate to search for new natural sources and technologies. The main field of these activities is intensive work related to the development of technologies for energy production using its renewable sources. These sources include wind, solar, rainfall, tides, sea waves and geothermal energy. In 2016, renewable energy sources met approximately $10 \%$ of human energy demand. In Poland, it is planned to increase production of energy from renewable sources up to $15 \%$ of energy in the national energy balance by 2020 . Over the last two decades, the use of wind and solar power has been the most intensive.

Wind turbines are built both on land and at sea. They can be constructed individually or in groups called wind farms. As the placement of farms on land near areas inhabited by people raises a lot of controversy, offshore wind farms are becoming more and more popular. This is a great alternative to conventional energy. The main advantages of offshore farms compared to land based are:
- greater wind strength and stability, which allows to increase the efficiency of the wind farm and minimize the negative impact on the national electricity network,

- no constraints on the size of the structure and easier transport of large elements, making it possible to obtain more power of the farm,

- minimized impact on people and landscape, so there is no problem of social opposition,

- favored the development of many species of fish and marine mammals because they are areas with limited navigation,

- much larger space where it is possible to install devices,

- creation of much more jobs at the construction stage than in the case of land based farms.

The most important disadvantages include:

- many times higher costs of construction, connection to the power grid, maintenance and operation of the power plant,

- highly corrosive and erosive environment,

- relatively difficult, limited access during renovation or maintenance,

- difficulties in navigation. 
Offshore wind energy is the future of the European renewable energy sector. The world's first offshore wind farm was built in 1991. The efficiency of offshore wind technologies is growing every year. Over $91 \%$ of investments in offshore wind energy are located in Europe. According to the latest report [28], unquestionable leaders in Europe in terms of installed capacity are Great Britain: 6,835 MW (1,753 wind turbines) and Germany, with installed capacity of 5,355 MW (1,169 wind turbines). The following places are occupied by Denmark: 1,266 MW (506 wind turbines), the Netherlands (1,180 MW, 365 wind turbines), Belgium (877 MW, 232 wind turbines). There is great potential in Poland for the construction of offshore wind farms. According to information provided by the Ministry of Maritime Economy and Inland Navigation, as of 04.05.2016, 13 permits for the construction of offshore wind farms were in force, of which 9 were paid. Significant interest of investors, including the largest international and domestic energy concerns, in the Polish market of the IMF, provides the basis for asserting that offshore wind energy may in the 20252050 perspective constitute an extremely important element of the national power system. The very favorable wind conditions (Fig. 1) and the shallow waters of the Baltic Sea significantly reduce the investment costs of offshore wind farms. The construction of offshore wind farms in Poland may contribute to the creation of approx. 31.5 thousand new jobs in the perspective of 2030 [8].

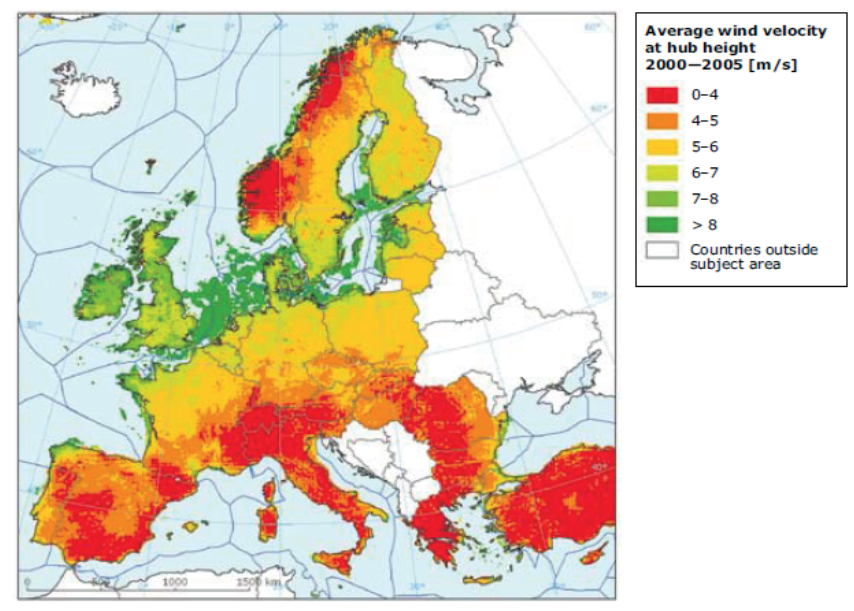

Fig. 1. Potential wind field localization in Europe [26]

Development of offshore wind farms requires appropriate calculation tools as well as normative and legal studies regulating the principles of designing these structures. This demand also includes data acquisition, design methods and analysis of wind farm construction foundations. Until 2010, the development of offshore wind farm projects focused on small depths (up to $20 \mathrm{~m}$ ) and close to land areas (up to $20 \mathrm{~km}$ ). It is expected that by 2030 , the location will be the standard on the seas with a depth of $60 \mathrm{~m}$ and $60 \mathrm{~km}$ from the mainland.

Offshore wind power foundations are mainly constructed as: monopile, gravity based foundation or gravity based structure (GBF or GBS), tripod, jacket or tripile (Fig. 2). Currently, most solutions for wind farm foundations are based on monopile technology. However, the more wind farms will move deeper into the sea to greater depths, the foundations will require major improvements, which also include floating platform technologies [27].

(a)

(b)

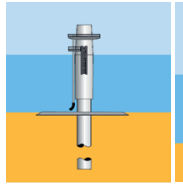

(c)

(d)

(e)
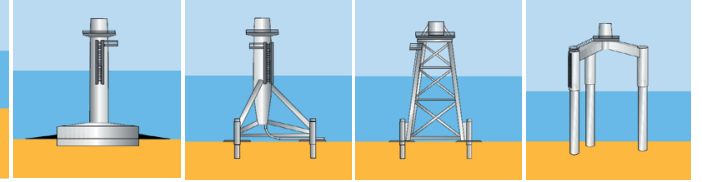

Fig. 2. Ways of wind farm foundations in the seabed [17] as of 2017:

(a) monopile ( $81.7 \%)$, (b) gravity-based foundation (GBF) (6.7\%),

(c) tripod (2.9\%), (d) jacket foundation (6.9\%), (e) tripile (1.8\%) [29]

During the whole period of use of the wind farm structure, different phases of the subsoil's work should be taken into account: earthworks, reinforcing or modifying the ground, foundation construction, assembly and disassembly of structures, launching, energy production, extreme wind, failure and others. In the case of offshore wind farms, impacts are associated with the nature of the marine environment. In this case, the main impacts are dynamic and in the design process it is necessary to perform numerical simulations taking into account possible impacts. For this purpose, advanced computational methods are used, striving for the most accurate assessment of the construction cooperation with the soil in a wide range of stress state occurring at various stages of construction and operation of the structure and in the limit state.

The main aim of this work is to present a new method of numerical interpretation of torsional shear test results in the aspect of acquiring material parameters for designing offshore wind farm foundation. The article is divided into the following sections: introduction, importance of the subject in terms of current achievements in the methods of estimating the initial value of the $G$ modulus and its significance in the issues of founding offshore objects, description of basic parameters characterizing soil stiffness, description of the resonant column - torsional shear apparatus (RC/ TS) with its advantages and disadvantages, presentation of results of exemplary analyses conducted in the RC / TS apparatus, proposal of an alternative methodology for interpretation of TS test results, presentation of several sample results of analyzes carried out with the proposed back analysis methodology, summary of the results obtained and a summary of conclusions.

\section{IMPORTANCE OF THE SUBJECT}

The wind power plant foundation is constantly subjected to dynamic loads, which results from the specificity of turbine operation and wind gusts. Turbine producers pay attention to the specific conditions for maximum settlement and tilting of the structure, the crossing of which may lead to high tipping moments. They also mention the important role of economic aspects [11].

At the same time, according to [11], there is a lack of generally available and specific guidelines for design in Polish 
standards. Author highlights that there were no instructions for conducting soil tests for those specific constructions. Therefore it was necessary to use the guidelines of the producer of a particular turbine or results obtained from experience in similar conditions.

According to the Polish Regulation of the Minister of Transport, Construction and Maritime Economy of April 27th 2012 regarding the determination of geotechnical conditions for the foundation of construction objects [25], objects of the third geotechnical category are distinguished, including atypical building structures, regardless of the complexity of soil conditions, the performance or use of which may pose a serious danger to users. That includes wind farms. At the same time, the regulation says that for construction objects of the third geotechnical category the scope of research should depend on the predicted degree of complexity of soil conditions as well as the specificity and character of the construction object or the type of planned geotechnical works and should specify mechanical soil parameters such as: internal friction angle, cohesion, undrained shear strength, and constrained or shear modulus, obtained in laboratory or field tests.

On the other hand, national publication highlights that it was common for the designer to have only one or two boreholes for each wind turbine and to determine the soil parameters using the B method according to PN-81 / B-03020. Not only that the amount of soil characteristics obtained in this way was insufficient to reliably design the foundation of the turbine, then the parameter values may deviate from the real state. Author warn that the geotechnical designer is forced to use further empirical formulas to determine the required parameters. The sizes obtained in this way may be far from the truth. The consequence of these calculations is the strengthening of the soil or piling in places where the structure can be directly placed. Therefore, attention should be paid to the fact that savings at the stage of geological or geological engineering documentation may contribute to the increase of the foundation costs in the final effect. At the end author mentions that designing the foundation of wind turbines, additional geotechnical problems should be considered in the form of soil behavior analysis in response to the dynamic / cyclical impact of the structure. Soil in the range of small deformations is defined by the initial shear modulus $G_{0}\left(G_{\max }\right)$ and constrained modulus $E_{0}\left(E_{\max }\right)$. The above parameters are obtained on the basis of specialist field tests (Seismic Cone Penetration Test SCPT, Seismic Dilatometer Marchetti Test SDMT probes) and laboratory tests (triaxial compression apparatus [10], resonant column) [21].

To sum up natural conditions are characterized by:

- lack of unequivocal guidelines for designing wind farm foundations,

- the necessity to take into account the non-linear variability of the subsoil,

- taking into account the soil stiffness in the area of small shear strains,

- freedom in the selection of a research method allowing for accurate assessment of ground soil parameters and at the same time leading to safe and economic solutions.
The article by Arany and others [1] proposes a simplified procedure for the design of wind turbine foundations, where it is recommended to use, among others, RC tests. The article points out that the dynamic stability of the structure can be endanger by changing the natural frequency of the structure over the entire lifetime of the turbine. Under the influence of environmental loads, a resonance phenomenon may occur causing a decrease in fatigue durability, worsening of SLS conditions and even a catastrophic loss of structural stability. Therefore, an important aspect is the observation of the impact of changes in soil stiffness on the natural frequency of the structure.

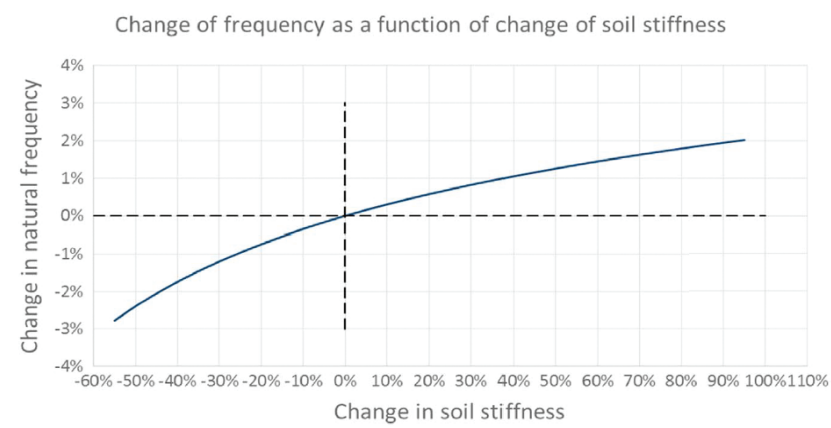

Fig. 3. Frequency change due to change in soil stiffness during the lifetime of the turbine [1]

Figure 3 shows that large change in soil stiffness results in small change in natural frequency (eg a $45 \%$ change in soil stiffness results in only $2 \%$ change in natural frequency). In the article [1], the authors point out that the prediction of cyclic monopile rotation is a leading aspect in the design of a wind turbine. For this reason, it is recommended to conduct soil tests in the resonance column for full, reliable forecasting of the long-term behavior of the monopile using the concept of threshold deformation (see [13]). An example of the practical use of resonance column test results for calculating wind power plant foundations is the work of Yu, Wang and Guo [20], which investigates the long-term dynamic behavior of a offshore monopile wind power plant structure settled in the sand and the effect of long-term cyclic and dynamic load on the subsoil. The research involved the use of a scaled model of a wind turbine planted on a monopole and subjected to various types of cyclic and dynamic loads using the mass suspended at the top of the model (Fig. 4). The analyzes used model soil research results based on RC tests carried out on sands by Drnevich, Hall and Richard [7] (Fig. 5). A relationship between the natural frequency of the structure and the change in soil stiffness was observed. The results of dynamic construction research have shown that the natural frequency of wind turbine construction increases with the number of cycles, but with a reduced rate of increase in the level of soil deformation. It was also found that this change is dependent on the level of shear strain of the subsoil. It has been noted that the results of the RC test can be used to explain the behavior of the structure model during tests and well reflect the soil reaction to the dynamic load on the structure. 


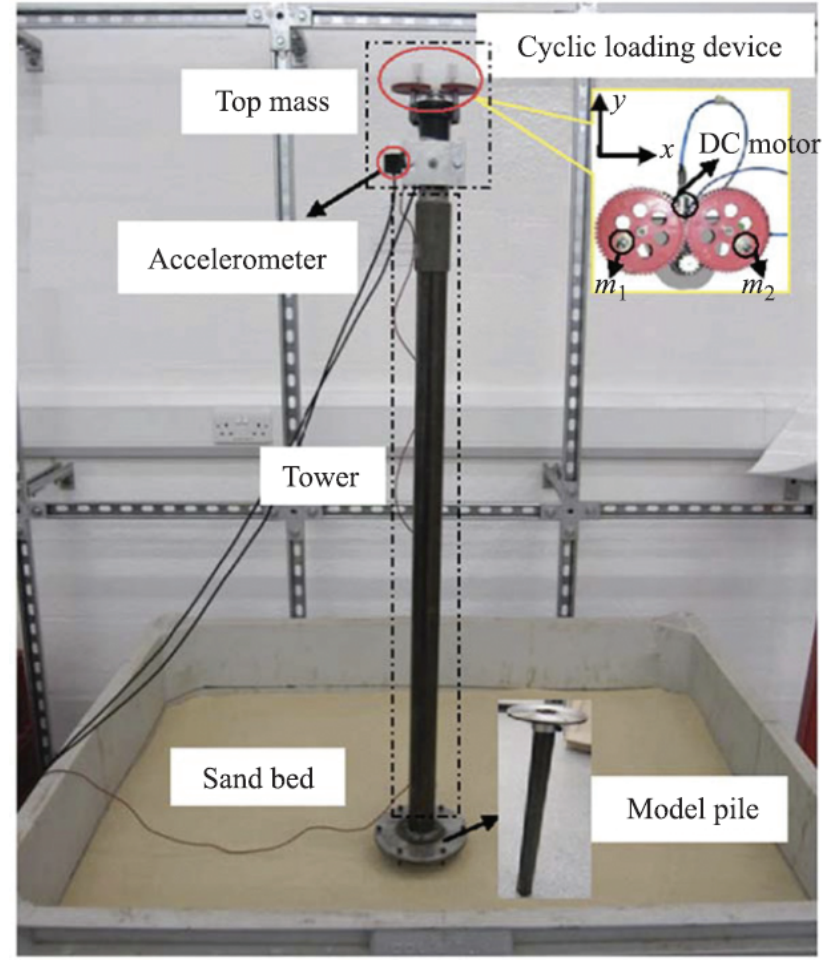

Fig. 4. Wind turbine model used in the research [20]
Despite the available model results and advantages of RC research, the most common practice is to use empirical correlation formulas, neglecting direct laboratory tests, which may not lead to optimal design effects.

\section{SOIL STIFFNESS PARAMETERS}

Modeling the behavior of structures in individual stages of loading requires knowledge of the mechanical parameters of the soil material appropriate to the calculation methods used, in particular those that describe its stiffness / deformability.

For wind power plants it shall be ensured that the properties of the soil correspond to the assumptions in the static and dynamic calculation. For the dynamic analysis, the distance of the natural frequency for the overall structure from the excitation frequencies is decisive in avoiding resonance. In the assessment of the expected natural frequencies, a parameter study is needed for the dynamic soil parameters; this shall be defined so that a range of possible soil types and soil properties is covered.

The stiffness / shear modulus is the basic mechanical parameter of the ground that allows the adoption of computational techniques used for materials exhibiting elastic properties. This parameter, however, is the instantaneous value in given conditions

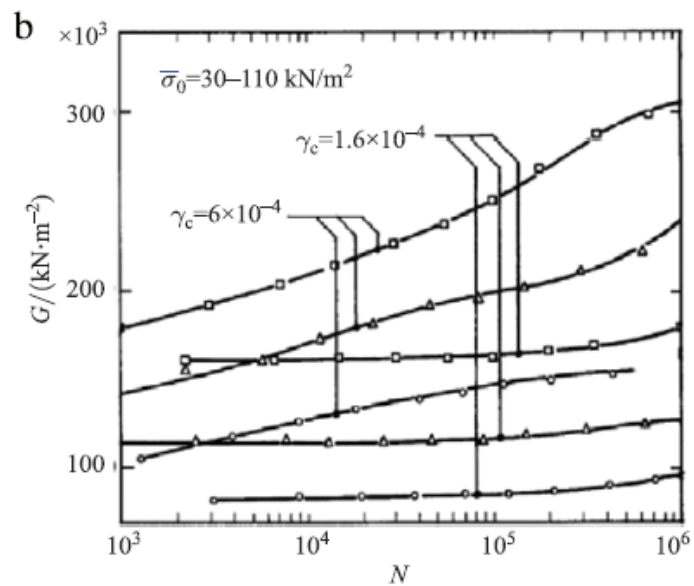

Fig. 5. Results of wind turbine model investigations: a) change in the natural vibration frequency of structure $f_{n} / f_{n \text {-initial }}$ (MST-1,2,3,4-sample number, $P$ - lateral load, D-pile diameter) [20]; b) change of soil shear modulus $G$ at various levels of $\gamma_{c}$ strain under dynamic load with $N$-cycles [7]
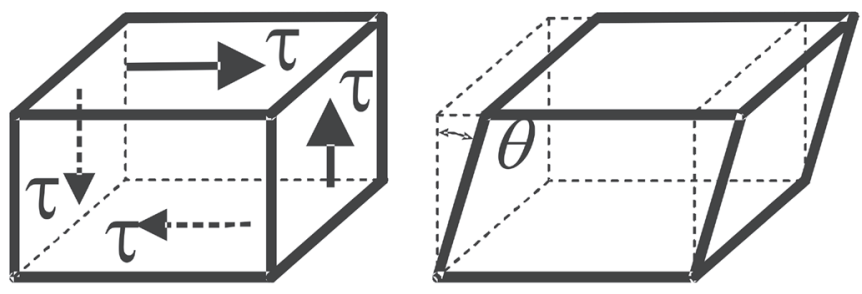

$$
G=\frac{d \tau}{d \gamma}, \quad \gamma=\operatorname{tg} \theta
$$

Fig. 6. Graphical definition of shear modulus $G$ defined by the level of strain and stress state, for a specific load history, its speed and character (static, dynamic, cyclic), dependent on the drainage conditions, and the type of structure which transfers the load. In addition, different types of stiffness modules are used, which correspond to the definitions determined by the theoretical basis of the used analytical method. The shear modulus G (Fig. 6) is now considered to be the basic parameter characterizing the stiffness of soils.

As the level of stress and strain increases, the stiffness modulus degrades. With more complex load modes like cyclic, dynamic, monotonically variable, the value of the stiffness modulus changes with the next load step (Fig. 7). The occurring deformations $\gamma$ can be divided into several characteristic ranges (Fig. 8). In the range of small and very small strains, the sample 
is characterized by the fully reversible behavior. The value of threshold strain (cyclic / volumetric threshold shear strain $-\gamma_{t v}$ ) is determined depending on the type of soil, (from $0.01 \%$ for coarse soils to $0.06 \%$ for fine-grained soils).

The value of the $G$ modulus corresponding to this threshold deformation falls to the value $0.85-0.60$ of the initial value of the module $G_{\max }$. Above this threshold value, the shape of the shear modulus degradation curve $G$ depends on the type of load, it may be static (monotonic) or dynamic (cyclic). The range of strains above the threshold deformation $\gamma_{t v}$ is called the range of plastic strain. The degradation of the shear modulus as the strain increases is higher for cyclic and dynamic loads and increases with the number of $N$ cycles. The range of these deformations according to some authors is called medium and large strains (Fig. 8), and above 1-3\% the residual (very large) deformations. The value of the shear modulus $G$ drops below $10 \%$ of the initial value.

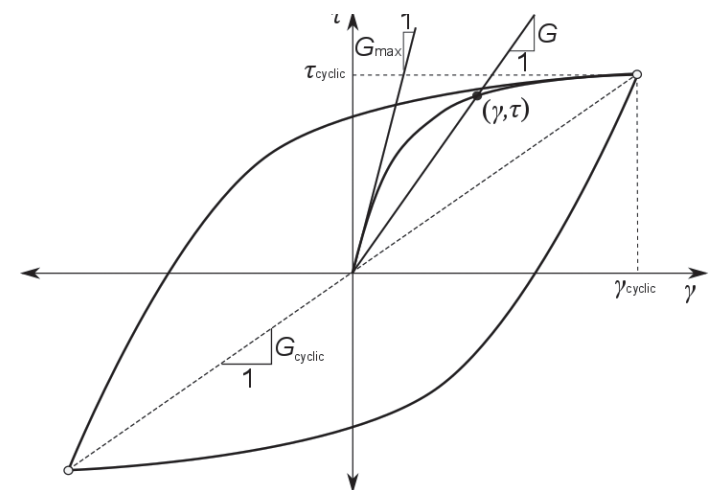

Fig. 7. Idealized graphic interpretation of $\tau-\gamma$ dependence in a cyclic, monotonic shear test of a soil sample [19]

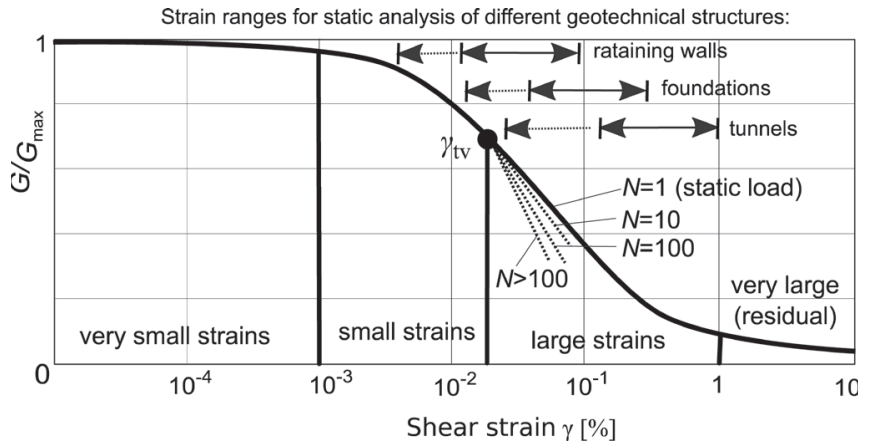

Fig. 8. Ranges of shear strains [6]

The initial $G_{\max }$ shear modulus is widely recognized as a parameter of the state of a given soil [14]. The shear modulus for very small deformations in dynamic problems is the same as the module $G_{\max }$ for static problems both "drained" and "undrained" conditions. In dynamic tests based on the measurement of propagation velocity of a shear mechanical wave in a solid medium, the initial shear modulus is determined from a simple dependence:

$$
G_{0}=G_{\max }=G_{d y n}=\rho V_{s}^{2}
$$

where:

$\rho$ - material density,

$V_{s}$ - shear wave propagation speed.
This dependence is used in many research methods whose main purpose is to measure the time of the waveform of the excited elastic wave on a separate section of the subsoil or in the soil sample. The module determined in this way corresponds to very small strains. Increasingly, the use of soil test using standard penetrometers (Cone Penetration Test CPT, Dilatometer Marchetti Test DMT, Pressuremeter Menard Test PMT) equipped with geophones and devices for generating a mechanical wave in the soil is more and more popular, thanks to which it is possible to measure in situ the velocity at which a seismic wave propagates in a separate layer of soil.

More precise measurements of the propagation speed of the shear wave in the ground are obtained by using indirect measurement methods. This method is a laboratory test in a resonant column, which uses the relationship between the frequency of natural vibrations and the speed of propagation of the elastic shear wave. The RC resonant column test is based on the relationship between the shear modulus $G$ and the resonant frequency of the tested soil sample. The functionality of the RC apparatus is extended for testing in various modes of loads and measurements, eg monotonic shear mode (TS) torsional shearing.

According to Project Requirements [24] minimum values for the soil shear modulus $G$ may be referred to DIN 4178: 200504 [30]. Designing the foundation of wind turbines towers, various limit states and computational situations should be considered. Standard limit states are not a big problem. The demanding problem is the analysis of subsoil reactions in response to dynamic and cyclic interactions from the structure as well as the analysis of mutual interaction of the substrate and structure, taking into account specific types of loads occurring in the marine environment. For land construction of wind farm towers, it is allowed to check the minimum dynamic rotational stiffness condition of the circular subsoil of the shallow foundation:

$$
k_{\varphi, d y n}>k_{\varphi l i m, d y n}
$$

$k_{\varphi, d y n}-$ dynamic rotational stiffness of the soil, determined from the formula:

$$
k_{\varphi d y n}=\frac{8 G_{0} r^{3}}{3(1-v)}
$$

where:

$v$ - average Poisson's ratio of soil,

$r$ - foundation radius,

$G_{o}$ - dynamic shear modulus for the ground,

$k_{\varphi l i m, d y n}$ - limit dynamic rotational stiffness of the subsoil defined by the turbine producer.

The fulfillment of the condition of dynamic stiffness of the soil for the foundation of offshore wind farm structures is insufficient. A comprehensive analysis of the behavior of these structures requires the performance of analytical work based on the results of extensive and advanced geotechnical laboratory tests, in situ as well as model tests (eg using geotechnical centrifuges [2]). 


\section{RC / TS APPARATUS}

Modern laboratory methods make it possible to research the soil in terms of small strains and allow better insight into the complex nature of the soil. One of the devices that enables multi-aspect analysis of mechanical properties of soil in the field of small deformations is resonant column (RC) combined with torsional shear apparatus (TS).

The RC / TS is precise measuring device that has been used in geotechnical engineering all over the world since the 1960s. The construction of the device is constantly modernized in order to broaden the spectrum of applications. WF8500 model from the British company Wykeham Farrance is a device belonging to the Institute of Building Engineering UWM in Olsztyn. The WF8500 is a RC apparatus - a resonant column - with the possibility of working in TS shear mode (Fig. 9). The apparatus is used to determine the mechanical features of the soil related to its stiffness, including the values of the strain modulus $G$ and the damping coefficient $D$. A detailed description of the of conducting the research and interpretation of results was included, among others in [18]. In the applied method, there is used propagation of elastic waves in the soil of the tested sample caused by its cyclic rotating. The device works in the frequency range of $10-300 \mathrm{~Hz}$, which allows generating a shear wave corresponding to the range of small and very small shear strains. The apparatus allows testing of a full cylindrical soil sample with a diameter of $50 \mathrm{~mm}$ or $70 \mathrm{~mm}$. The most important advantages of the device are:

- the ability to conduct RC, TS and FD (free decay) tests on the same soil sample,

- fully automated processing of results and an immediate result $(G, D)$,

- smooth adjustment of the level of deformation and the value of the confining pressure at which the parameters $G$ and $D$ are determined (this allows to determine the relationship $G(\gamma)$ and $D(\gamma)$ for different values of confined pressure).

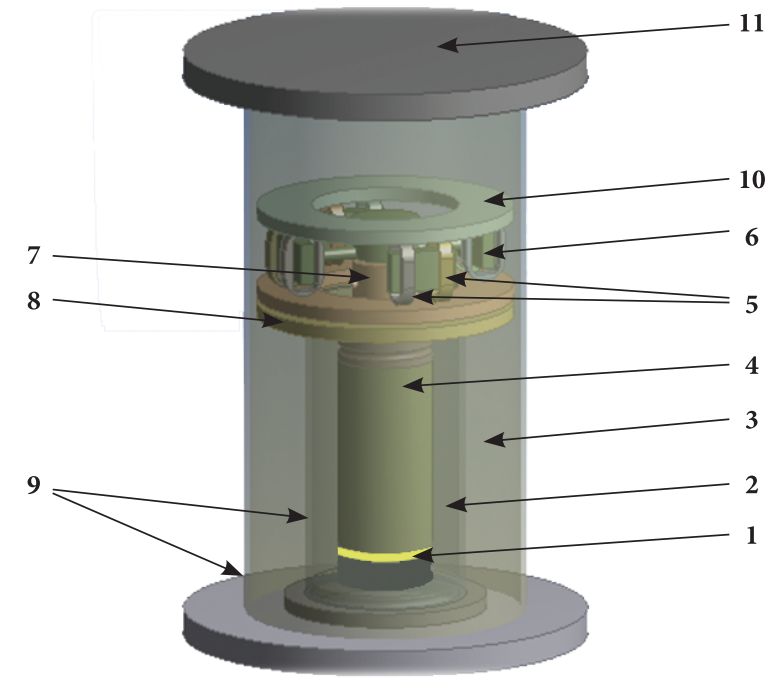

Fig. 9. Scheme of RC/TS apparatus: 1 - porous stone, 2 - water in the inner cylinder, 3 - compressed air in the external cylinder, 4 - cylindrical soil sample, 5 - stator coil, 6 - rotor neodymium magnet, 7 - sample top cap, 8 - stator mounting ring on the inner cylinder, 9 - transparent cylinders made of polycarbonate, 10 - stator ring, 11 - cover closing the external cylinder
The device is not without flaws - the most important from the point of view of scientific research is the completely closed device control software that prevents setting individual load / strain paths (eg it is not possible to extend the time of registration of geometric parameters of the sample after TS testing to observe plastic-durable part of the shear strains of the tested soil).

Figures 10-12 show screen shots of exemplary RC, TS and FD test results, on which graphs of measured physical quantities were graphically depicted and the results of automatically interpreted mechanical features of the materials examined were tabulated.

Despite the very complex and difficult to implement the soil sample installation process in the apparatus, there should be emphasized that the test in the resonance column is considered to be highly reliable, practical and relatively convenient in terms of interpretation of measurements (see [14]).

\section{NEW METHODOLOGY FOR DETERMINING THE SHEAR MODULUS}

Obtaining a full description of the behavior of the tested material under a cyclic load requires reconstruction of the full load path taking into account the incremental changes in stiffness (in feedback) of the path function (see [9]). In numerical calculations, the simulation of the hysteresis loop phenomenon (the Masing rule) is implemented by implementing in computer applications special cases of constitutive laws of non-linear elasticity or elasticity-plasticity (eg [3] and [5]). In the state-ofthe-art, you can find many interesting mathematical / numerical solutions that allow you to simulate even quite complex (nonelliptical) shapes of these loops (eg [16] and [4]) as well as their experimental modeling (eg [23]). To carry out numerical calculations related to the back analysis of TS test results, a modeling concept for the Masing rule was developed, which was programmed in $\mathrm{C}++$ in the form of the computer application TS.exe. Fig. 13 shows the internal structure of the TS.exe program - calculations are carried out in the form of sequentially executed procedures and functions (names are marked in italics).

Forcing the shearing of the numerical representation of soil sample is conducting by applying increments of the angle of rotation of its upper surface $(\Theta)$ calculated in each, the contractual time step $(t)$ and, according to the formulas:

$$
\begin{gathered}
t=\frac{2 i \pi}{n} \\
\Theta^{i+1}=\Theta_{\max } \sin (t) \\
\Delta \Theta^{i+1}=\Theta^{i+1}-\Theta^{i}
\end{gathered}
$$

where:

$t$ - contractual time calculated from the value of the step $i$, $n$ - number of steps set in the input data,

$\Theta^{i, i+1}$ - rotation angle, respectively: previous $(i)$ and next $(i+1)$, $\Theta_{\max }$ - the maximum torsion angle given in the input data.

The phenomenon of stiffness degradation is obtained by reducing the value of the Kirchhoff modulus $G(\gamma)$, and as 


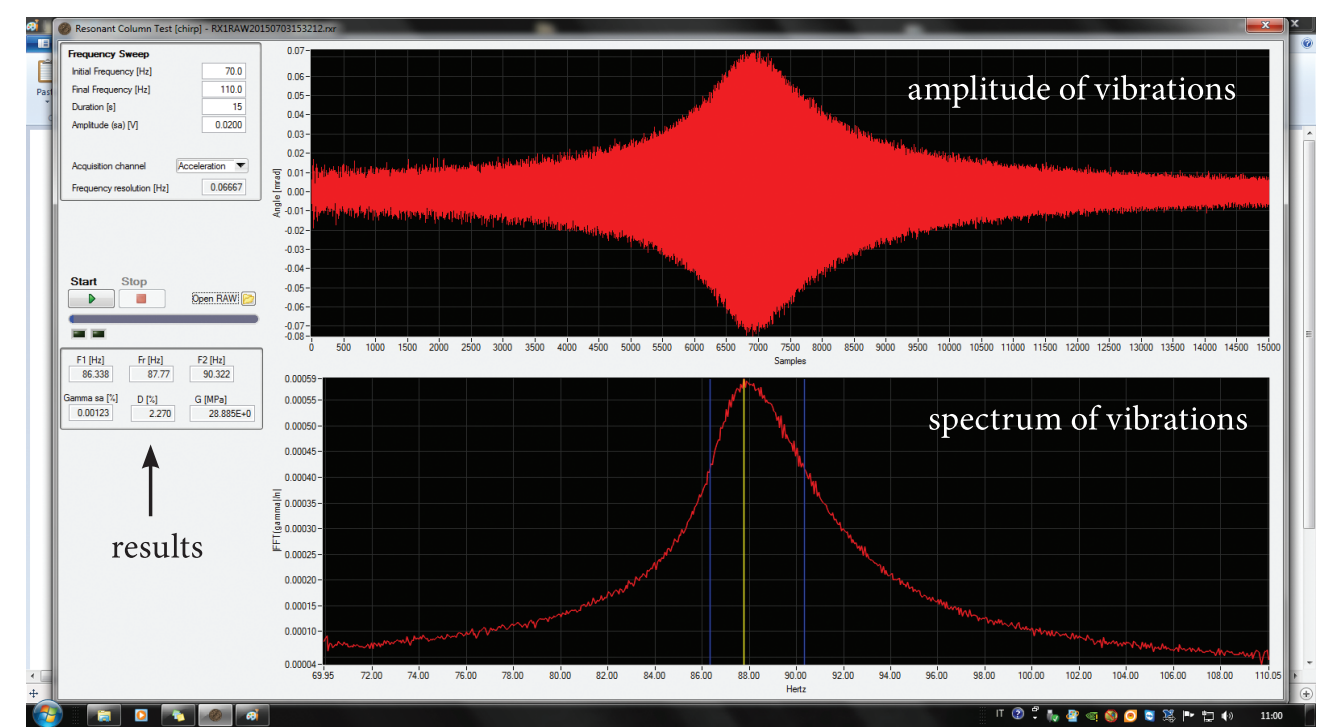

Fig. 10. View of the screen with $R C$ test results

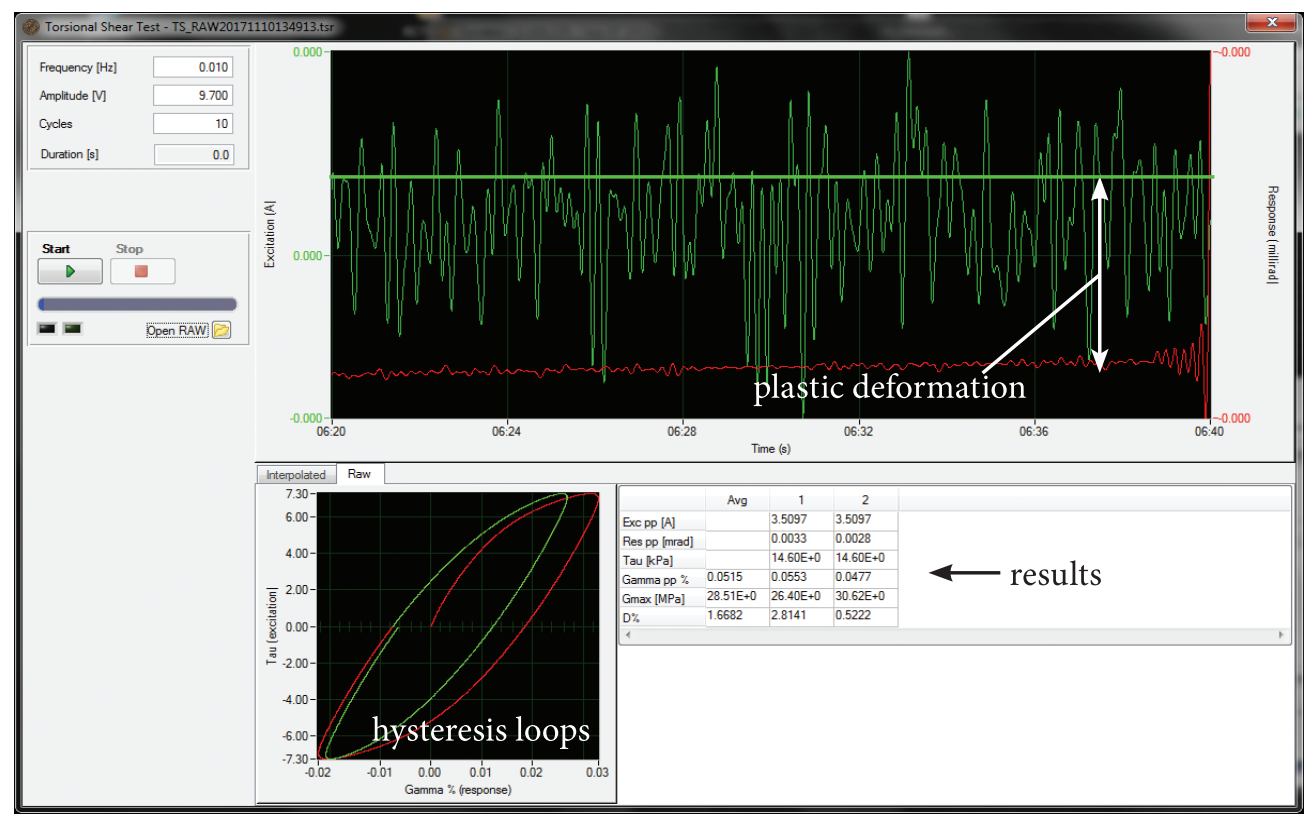

Fig. 11. Screen view with TS test results

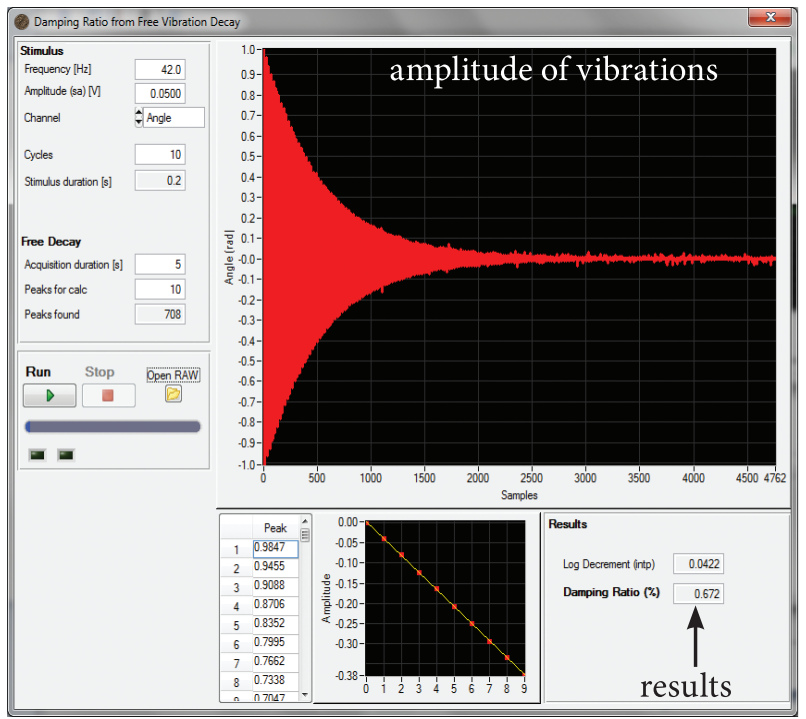

Fig. 12. View of the screen with the results of the FD test 


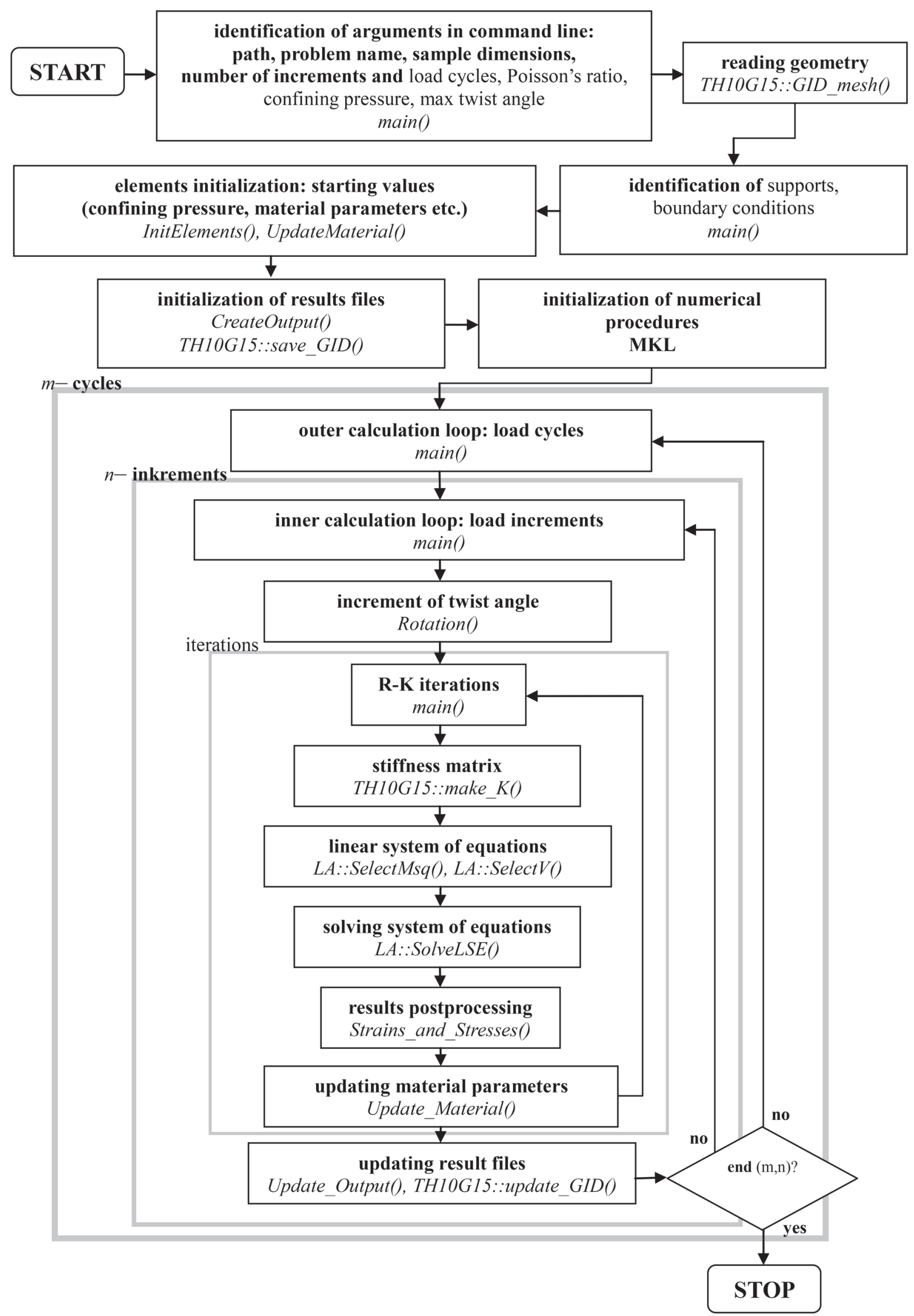

Fig. 13. The internal structure of the TS.exe application 
a consequence the Young modulus $E(G(\gamma), v)$ keeping the Poisson's ratio $v$ constant.

$$
E(\gamma)=2 G(\gamma)(1+v)
$$

The anisotropic changes in the mechanical properties of the sample material induced by shearing are simulated by the resultant effect of differing stiffnesses at individual integration points in the volume of a given finite element. The procedure for the modified method of tangent stiffness is shown in Fig. 14.

The adopted simplification regarding the modeling of nonuniformly degraded stiffness in the volume of material is completely acceptable, taking into account the aspects of the target use of the obtained calculation results to solve practical problems occurring in marine engineering. Additionally allows to consider the local variation of stiffness changes within each element independently and to observe the effects of their homogeneity within the entire system.

The proposed concept of determining the non-linear relation $G(\gamma)$ consists in iteratively matching the relation $\tau(\gamma)$, having the form of a hysteresis loop obtained from FEM simulation calculations to results obtained from TS soil research. The most commonly used technique is to perform numerical simulation of the experiment and to estimate the quality of the solution based on the adopted objective function, eg:

$$
L=\sum_{n} w\left(\tau_{\gamma}^{e}-\tau_{\gamma}^{c}\right)^{2}
$$

in which: $\tau_{\gamma}^{e}$ - measured (experimental) values $\tau$ for given values $\gamma,{ }^{\gamma} \tau_{\gamma}^{c}$ - determined (calculated) from the theoretical / numerical model of values $\tau$ for given values $\gamma, w$ - weights assigned to analyzed points (computing nodes), $n$ - number of points (nodes) with compared values $\tau(\gamma)$.

The task constructed in this way is a complex problem and it may turn out that it is wrongly posed in the sense of Hadamard, which may result directly in difficulties in obtaining the convergence of the iterative process. However, adjusting the results of calculations to the results of experimental research can be carried out in stages, limiting the optimization process to finding coordinates of a selected subset of points associated with previously corresponding points in a subset of experimental data. Analysis of subsequent points and optimization of the local relation $G(\gamma)$ allows to simplify the entire process and significantly improve its convergence. The proposed algorithm is shown in Fig. 15.

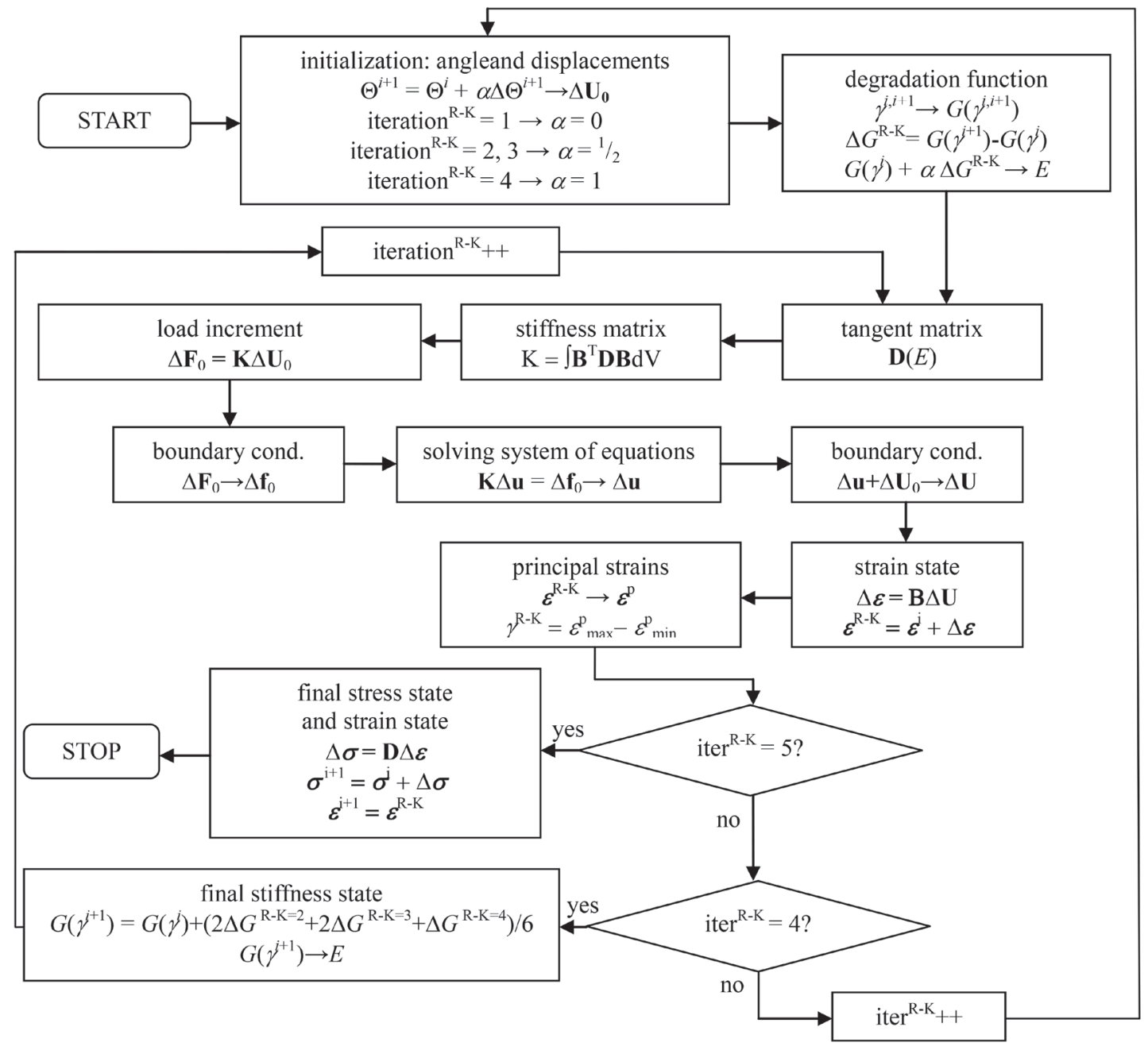

Fig. 14. The algorithm of the modified tangent stiffness method 


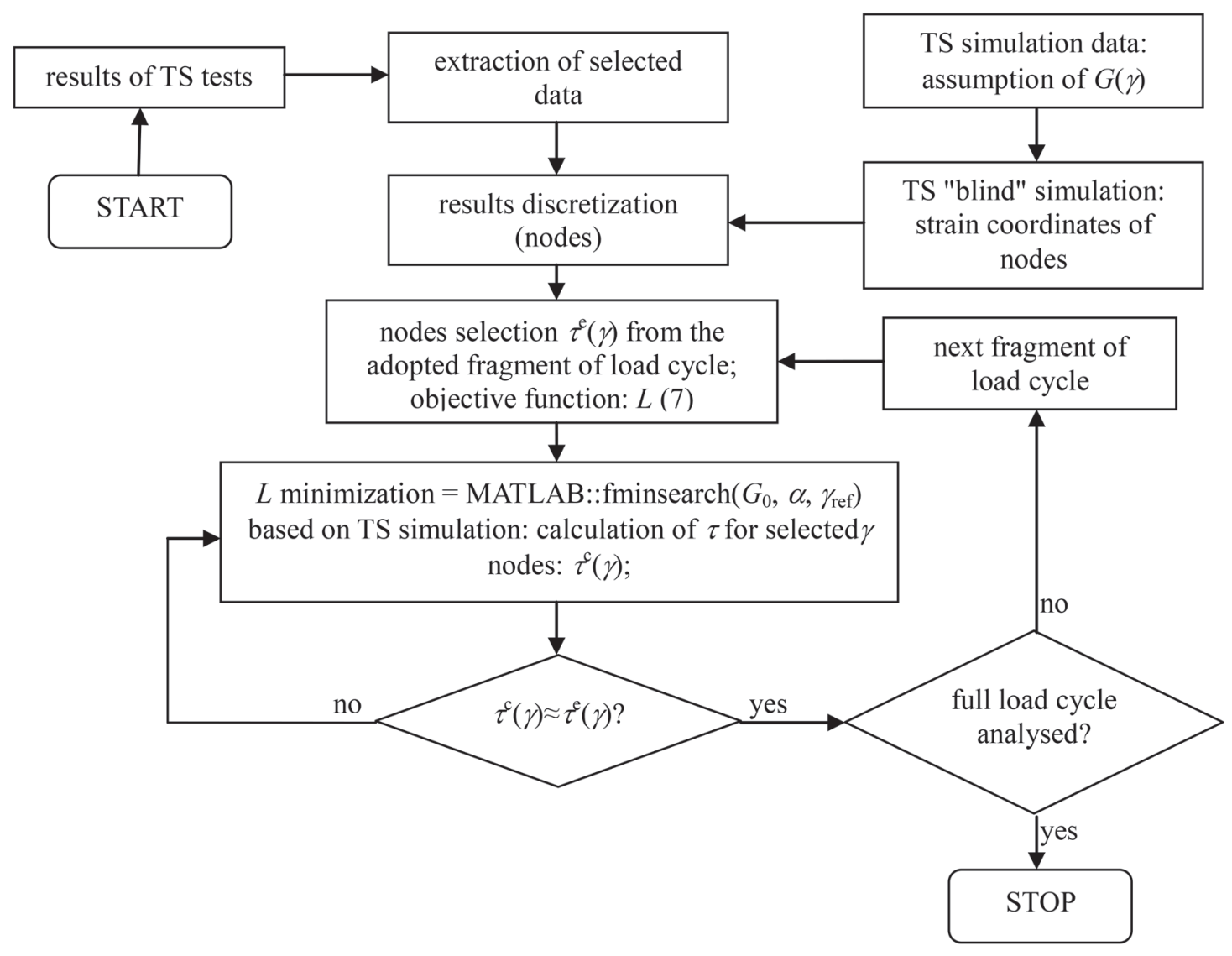

Fig. 15. The algorithm of searching for the local dependence of $G(\gamma)$ by back analysis

The first stage of the algorithm implementation is to discretize the results of the experimental study. It should strictly correspond to the calculation points realized by the numerical application of the TS test. Considering the fact that the experimental data already have the form of a set of points (the sampling rate of the RC / TS apparatus is $100 \mathrm{~Hz}$ ), the preparation of the set of computational nodes consists in the selection of measuring points with the possible application of linear interpolation in the case when the node's elevation is between measurement points.

Due to the assumption that $G$ values depend on only one argument - shear strain, a set of selected points was divided into four subsets representing four stages of sample shearing (Fig. 16):

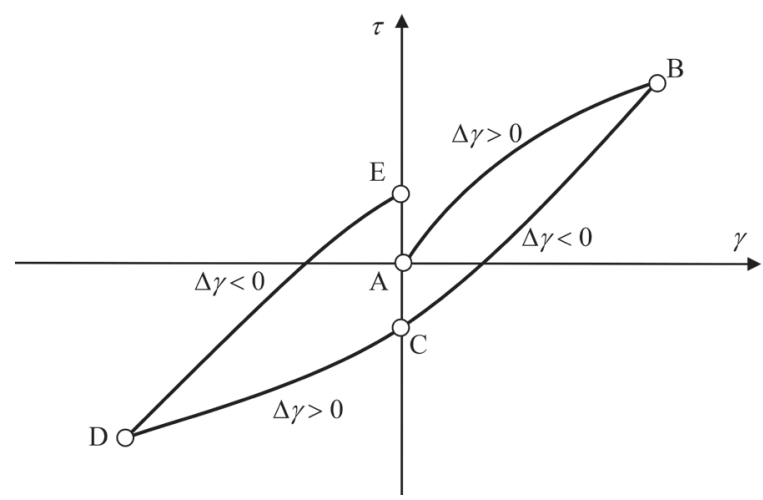

Fig. 16. Split of the shear cycle of a material sample into four phases
- primary torque load: $\gamma_{A B} \in\left[\gamma_{A}=0, \gamma_{B}=+\gamma_{\max }\right]$;

- primary unloading and secondary torque load with the opposite return until reaching $\gamma_{C}=0: \gamma_{B C} \in\left[\gamma_{B}=+\gamma_{\max }, \gamma_{C}=0\right]$;

- continuation of the secondary load:

$\gamma_{C D} \in\left[\gamma_{C}=0, \gamma_{D}=-\gamma_{\max }\right]$

- secondary unloading and subsequent loading with a torque with a positive sign to achieve

$\gamma_{E}=0: \gamma_{D E} \in\left[\gamma_{D}=-\gamma_{\max }, \gamma_{E}=0\right]$, where the relations are determined separately $G(\gamma)$. These relationships can be obtained in the form of explicit relationship after assuming the general form of the function $G(\gamma)$ arbitrarily assumed the function in [16] on the form:

$$
\begin{gathered}
G(\gamma)=G_{0} \Gamma\left(\gamma, \alpha, \gamma_{r e f}\right) \\
\Gamma\left(\gamma, \alpha, \gamma_{r e f}\right)=\frac{1-\alpha}{1+\frac{\gamma}{\gamma_{r e f}}}+\alpha
\end{gathered}
$$

in which:

$G_{0}$ - maximum value of the modulus

$G, \gamma_{\text {ref }}$ - reference value of shear strain,

$\alpha$ - a constant that can be interpreted in general as [16]:

$$
\alpha=\frac{G_{\min }}{G_{0}}
$$


where: $G_{\min }$ means the minimum value of the $G$ modulus corresponding to $G(\gamma=+\infty)$.

Assuming the form of variability of shear modulus values according to formulas (8) and (9), three basic parameters were defined: $G_{0}, \alpha, \gamma_{\text {ref }}$, which determine the path and values of $G(\gamma)$.

In the process of minimizing the purpose function, the method of non-gradient optimization, belonging to the group of direct search methods, the Nelder-Mead algorithm was used [15]. The algorithm consists in the sequential generation of symplexes defined $n+1$ vertices in the case of optimization of the $n$-argument objective function.

\section{EXAMPLES OF APPLICATION OF PROPOSED METHODOLOGY}

In order to demonstrate the effectiveness of the proposed methodology for determining the value of the shear modulus, several TS tests were carried out on selected cohesive and noncohesive soil samples. Selected samples are characterized in Table 1. The research team in Institute of Civil Engineering in Olsztyn carried out experiments in a wide range of confining pressure in the TS apparatus - from $0 \mathrm{kPa}$ to $500 \mathrm{kPa}$. Some of them were selected for the numerical back analysis. All fully cylindrical samples were not saturated, silt samples had natural structure and water content, sand samples were reconstituted. Table 2 presents the parameters of numerical models of the analyzed soil samples.
Numerical models of samples discretised with tetrahedral elements with ten nodes and fifteen Gaussian points (TH10G15). The adopted number of nodes and elements in numerical analyzes are not critical values - the numeric application used in back analyzes is not sensitive to the density of discretization. The adopted number of load steps is the minimum value guaranteeing a smooth path of stiffness variability in the obtained numerical results. The other parameters result from the features measured during the TS tests.

Figures 17-22 show experimental and computational relations $\tau(\gamma)$ with the resultant dependencies $G(\gamma)$ for individual load / unload steps for one full Masinga cycle. As can be seen, reconstructing the results of an experimental study by calculations requires the use of a function $G(\gamma)$ the function describing the degradation of the stiffness of the material progressing along with the increase in the value of the shear strain. It should be emphasized that, by interpreting the obtained results, the relation $G(\gamma)$ referring to $1 / 2-3 / 4$ of hysteresis loop as supplementation of stiffness changes initiated by the primary material unloading corresponding to the $1 / 4-1 / 2$ fragment of this loop.

However, it should be remembered that forms of relation $\tau(\gamma)$ on both sides of the point $\gamma=0$, connecting the second and third stage of twisting the sample (point $C$ in Figure 16), can significantly differ and then separate relations $G(\gamma)$ can represent well the variable mechanical properties of the material being tested.

The obtained relations can be used for designing the offshore wind farm foundations taking into considerations shear modulus values for $\gamma=10^{-6}$ independently in the case of positive

Tab. 1. Characteristics of tested soil samples

\begin{tabular}{|c|c|c|c|c|c|c|c|c|c|c|}
\hline $\begin{array}{l}\text { Sample } \\
\text { symbol }\end{array}$ & Soil & $\begin{array}{c}\text { Diameter } \\
{[\mathrm{cm}]}\end{array}$ & $\begin{array}{c}\text { Height } \\
{[\mathrm{cm}]}\end{array}$ & $\begin{array}{c}\text { Weigh } \\
{[\mathrm{g}]}\end{array}$ & $\begin{array}{c}D_{50}^{*} \\
{[\mathrm{~mm}]}\end{array}$ & $e^{\star}[-]$ & $\begin{array}{c}\text { Water } \\
\text { content } \\
{[\%]}\end{array}$ & $\begin{array}{c}\text { Volumetric } \\
\text { density } \\
{\left[\mathrm{g} / \mathrm{cm}^{3}\right]}\end{array}$ & $I_{C}{ }^{*} / I_{S}^{*}$ & $\begin{array}{c}\text { Cell } \\
\text { pressure } \\
{[\mathrm{kPa}]}\end{array}$ \\
\hline TS3249 & Silt & 6.96 & 14.16 & 1007.9 & 0.047 & 0.42 & 26.8 & 1.871 & 0,4 & 120.6 \\
\hline TS3935 & Sand & 7.28 & 14.31 & 1093.0 & 0.33 & 0.41 & dry & 1.835 & 0.94 & 48.3 \\
\hline TS4913 & Sand & 7.28 & 14.30 & 1093.1 & 0.33 & 0.41 & dry & 1.836 & 0.94 & 48.6 \\
\hline TS5558 & Sand & 7.00 & 14.30 & 1109.7 & 0.33 & 0.38 & 7.8 & 2.016 & 0.99 & 28.6 \\
\hline TS5919 & Sand & 7.00 & 14.31 & 1029.0 & 0.33 & 0.38 & dry & 1.868 & 0.97 & 28.0 \\
\hline
\end{tabular}

${ }^{*} D_{50}-$ nominal particle size, $e-$ void ratio, $I_{C}$ - consistency index, $I_{S}-$ compaction index

Tab. 2. Parameters of the sample models accepted for the calculation

\begin{tabular}{|c|c|c|c|c|}
\hline Sample symbol & Number of nods & Number of elements & $\begin{array}{c}\text { Number of load } \\
\text { increments in the cycle }\end{array}$ & $\begin{array}{c}\text { The minimum } \\
\text { angle of twist } \\
{[\mathrm{mRad}]}\end{array}$ \\
\hline TS3057 & 305 & 142 & 80 & $\begin{array}{c}\text { The maximum } \\
\text { angle of twist } \\
{[\mathrm{mRad}]}\end{array}$ \\
\hline TS3249 & 284 & 125 & 80 & -16.6 \\
\hline TS3935 & 295 & 134 & -7.9 \\
\hline TS4913 & 295 & 134 & -0.8 \\
\hline TS5558 & 303 & 140 & 80 & -1.3 \\
\hline TS5919 & 303 & 140 & 80 & -2.7 \\
\hline
\end{tabular}


loading, unloading, negative re-loading and unloading of the soil (in the case of the sample TS5558: $27 \mathrm{MPa}, 30 \mathrm{MPa}, 10 \mathrm{MPa}$ and $20 \mathrm{MPa}$, respectively). However, the best approach is to use full $G(\gamma)$ analytical relationships in foundation design, using numerical applications based on FEM.

Although the obtained relations are in the form of mathematical formulas allowing their use in any range of arguments, it is necessary to avoid extrapolating Kirchhoff's module values from obtained $G(\gamma)$ relations beyond the range of maximum values of shear strains generated during the test. The only possibility of extending the scope of interpretation is to increase the value of the angle of shearing the material sample in the TS test (the device allows the measurement of the angle of torsion up to $\pm 30 \mathrm{mRad}$, but due to the control of the electric voltage generating the torque - the achievement of certain deformations is conditioned by the momentary stiffness of the sample).

Obviously, it is necessary to emphasize the extremely important fact that each extrapolation of results carries the risk a)

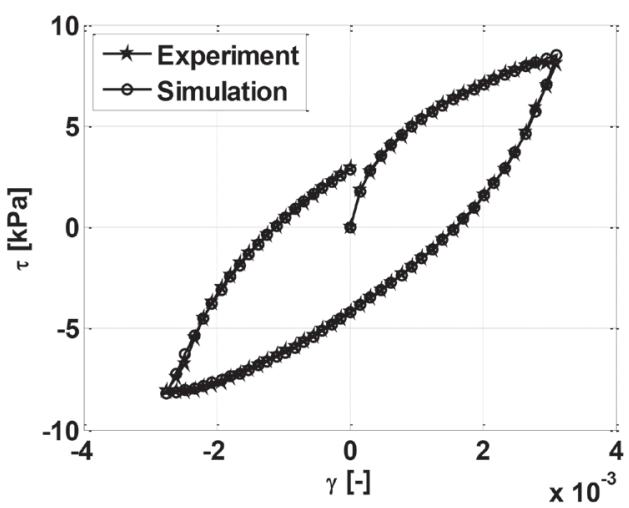

b)

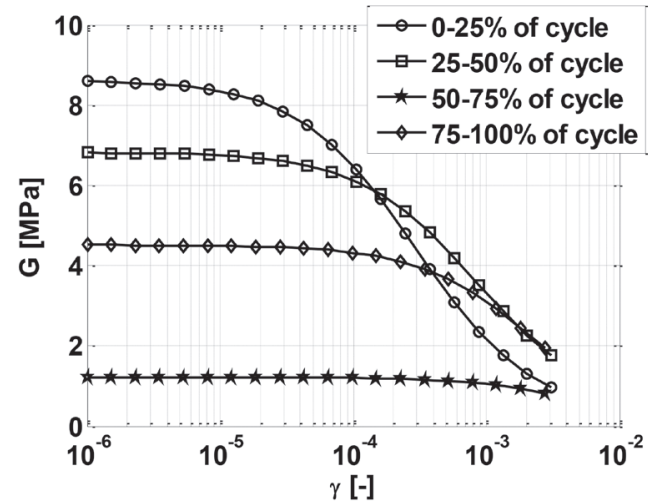

Fig. 17. Analysis results for sample TS3057: a) visualization of matching the numerically obtained relation $\tau(\gamma)$ to the experimental relation; $b$ ) the resultant relations $G(\gamma)$

a)

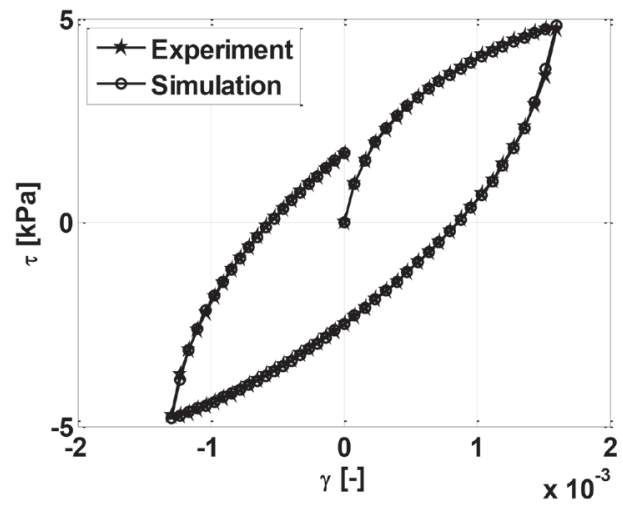

b)

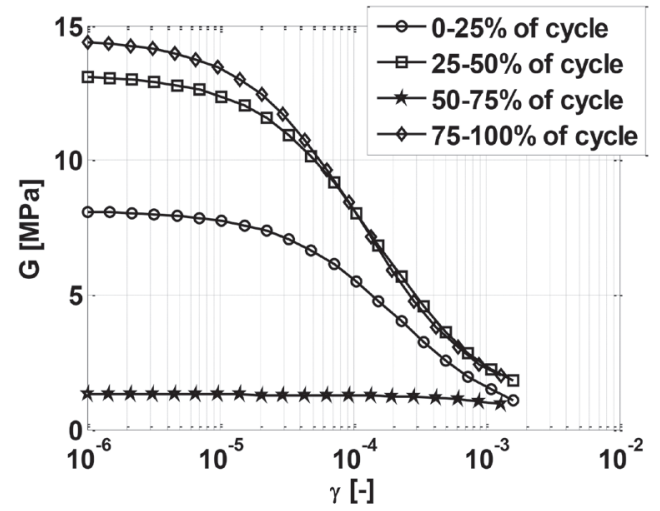

Fig. 18. Analysis results for sample TS3249: a) visualization of matching the numerically obtained relation $\tau(\gamma)$ to the experimental relation; $b$ ) the resultant relations $G(\gamma)$

a)

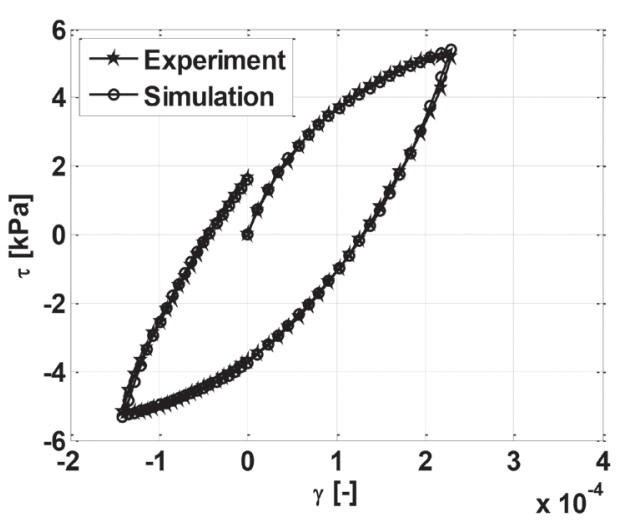

b)

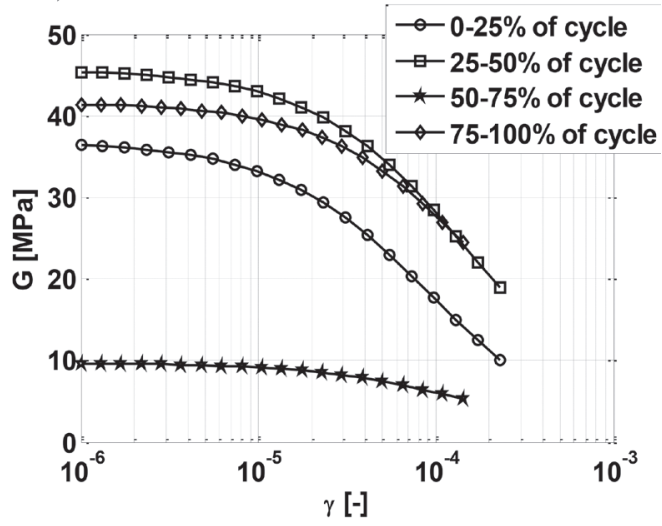

Fig. 19. Analysis results for sample TS3935: a) visualization of matching the numerically obtained relation $\tau(\gamma)$ to the experimental relation; $b$ ) the resultant relations $G(\gamma)$ 
of strong disturbances and distortions in the area that goes beyond the permissible range of arguments for the designated functions and therefore, it's not advisable. The results in the range of large shear strains can be successfully supplemented with traditional laboratory tests (eg in a triaxial compression apparatus with on-specimen sensors).

In the presented examples of automated interpretation of laboratory test results, selected possibilities of conducting numerical analyses with the use of MES have been demonstrated, which in their application are limited only by the imagination of experimenters (see numerical analyses based on the inclusion of soil microstructure, eg [22]).

The back analysis of TS test results for subsequent cycles proceeds in the same way as for the first cycle, but such analyses have not been carried out and will be the subject of further research.

a)
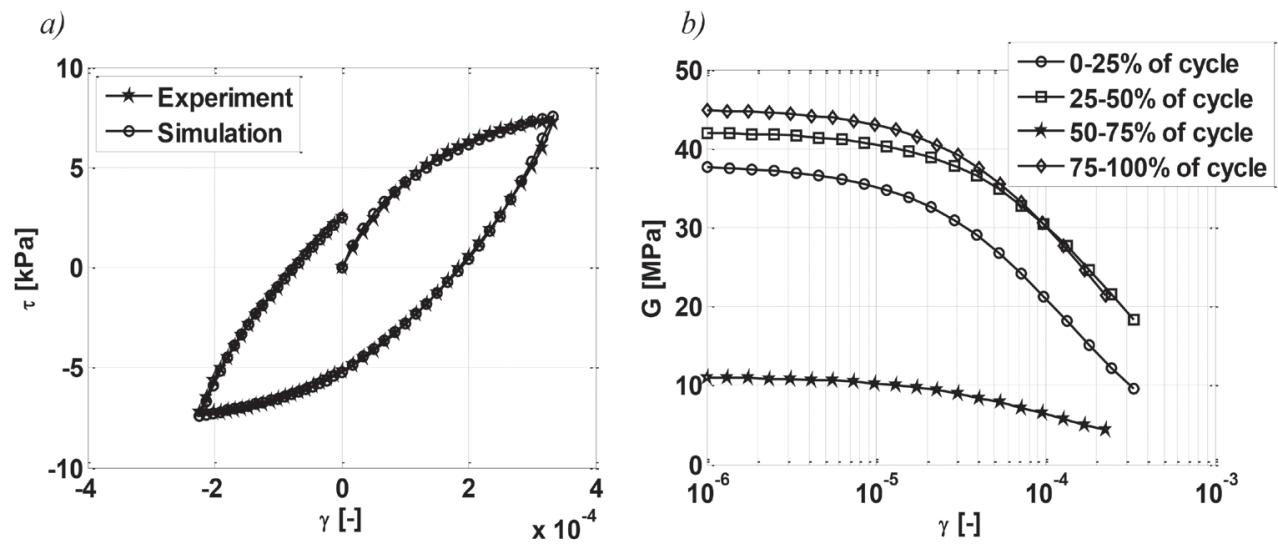

Fig. 20. Analysis results for sample TS4913: a) visualization of matching the numerically obtained relation $\tau(\gamma)$ to the experimental relation; $b$ ) the resultant relations $G(\gamma)$

a)

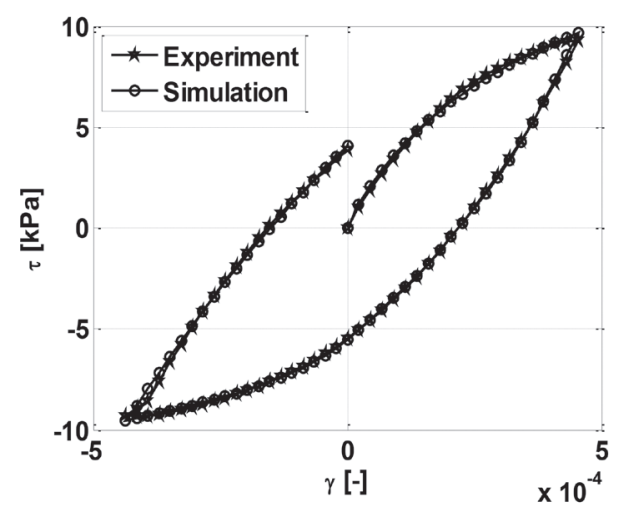

b)

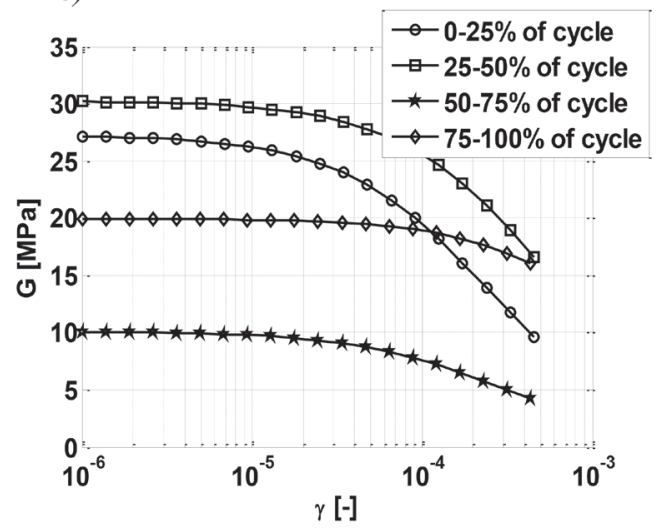

Fig. 21. Analysis results for sample TS5558: a) visualization of matching the numerically obtained relation $\tau(\gamma)$ to the experimental relation; $b$ ) the resultant relations $G(\gamma)$

a)

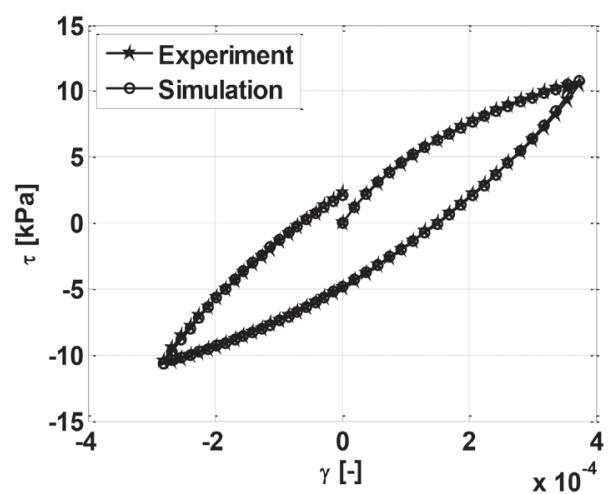

b)

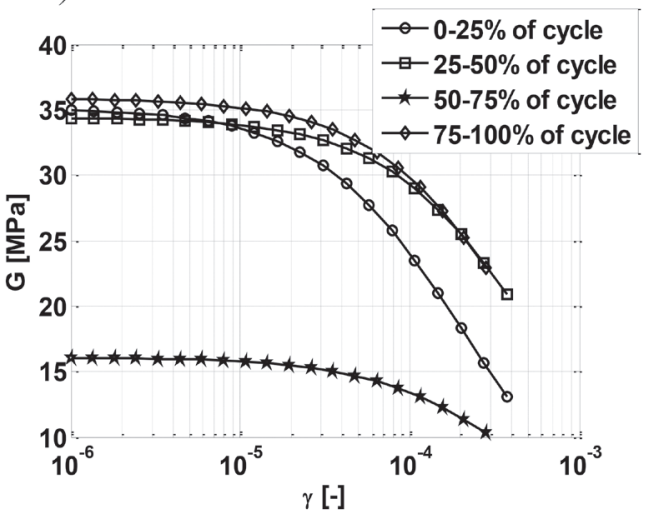

Fig. 22. Analysis results for sample TS5919: a) visualization of matching the numerically obtained relation $\tau(\gamma)$ to the experimental relation; $b$ ) the resultant relations $G(\gamma)$ 


\section{SUMMARY AND CONCLUSIONS}

Presented in this paper subject estimating the value of soil strain parameters is certainly an important part of the process of implementing the concept of foundation engineering of offshore objects. The proposed method of interpretation of the results of the torsional shear test can be successfully applied in practical issues, giving information not only about the initial value of the shear modulus, but also about the nature of its degradation. Performing back analyses based on FEM simulations can be used without any limitations, especially in the case of numerical tool calibration, which will be carried out with calculations that dimension the foundations of the designed offshore building. Unfortunately, the method is not without flaws. Its basic drawback is the lack of proof for the universality of the designated relations $G(\gamma)$ they are characteristic of the specific implementation of constitutive law used in the numerical tool, which has been calibrated using a back-analysis technique.

In the near term, the authors plan to modify their RC / TS apparatus to allow long-term observation of plastic deformations of the soil (see [12]) during the TS test after the impact of the torque moment has ceased. This will allow a quantitative assessment of the share of permanent deformation in the total deformation of the material under investigation, which will allow to clarify the mathematical description of phenomena occurring during torsional shearing of soil materials.

\section{BIBLIOGRAPHY}

1. [Arany L., Bhattacharya S., Macdonald J., Hogan S.J. (2017), Design of monopiles for offshore wind turbines in 10 steps, Soil Dynamics and Earthquake Engineering, pp. 126-152.

2. BaŁachowski L. (2017). Physical modelling of geotechnical structures in ports and offshore. Polish Maritime Research Special Issue S1, 24(93), pp. 4-9.

3. BENZ T. (2007). Small strain stiffness of soils and its numerical consequences ( $\mathrm{PhD}$ dissertation), Universitat Stuttgart, Germany.

4. Chen X-L., Jin X., TaO X-X. (2008). Comparisons of 5 types of soil dynamic nonlinear constitutive models in seismic response of site. The $14^{\text {th }}$ World Conference on Earthquake Engineering, Beijing, China.

5. Chiang D.Y. (1992). Parsimonious modeling of inelastic structures ( $\mathrm{PhD}$ thesis), California Institute of Technology, Pasadena, USA.

6. Diaz-Rodriguez J.A., Lopez-Molina J.A. (2008), Strain thresholds in soil dynamics. The 14-th World Conference on Earthquake Engineering, October 12-17, 2008, Beijing, China.
7. Drnevich V.P., Hall J.R., Richard F.E. (1967), Effects of amplitude of vibration on the shear modulus of sand, in: Proc., Int. Symp. on Wave Propagation and Dynamic Properties of Earth Mat., Albuquerque, N.M., pp. 189-199.

8. Duda M., MikoŁajuk H., Okrasa S. (2009). Prognoza bilansu energetycznego Polski do 2030 r. Materiały XXIII Konferencji „Zagadnienia surowców energetycznych i energii w gospodarce krajowej, Zakopane 11-14 X 2009.

9. JARDINE R.J. (1992). Some observations on the kinematic nature of soil stiffness, Soils and Foundations, 32(2), pp. 111-124.

10. JAStrzęBSKA M. (2010). The external and internal measurement effect on shear modulus distribution within cyclic small strains in triaxial studies on cohesive soil, Int. Conf. on Experimental Mechanics ICEM14, European Physical Journal, EPJ Web of Conferences 6, 2014.

11. KRól M. (2013), Problemy związane z posadowieniem elektrowni wiatrowych, Geoinżynieria drogi mosty tunele, 44(3), pp. 44-46.

12. Li J., Chen S., JiAng L., (2015), Dynamic strength and accumulated plastic strain development laws and models of the remolded red clay under long-term cyclic loads: laboratory test results, Polish Maritime Research, Special Issue S1, 22(86): pp. 89-94.

13. Lombardi D, Bhattacharya S, Muir Wood D. (2013) Dynamic soil-structure interaction of monopile supported wind turbines in cohesive soil, Soil Dynynamic Earthquake Engineering pp. 165-80.

14. Mayne P.W., Coop M.R., Springman S.M., Huang A-B., ZoRnBERg J.G. (2009), Geomaterial behavior and testing.Proc. of 17-th International Conference on Soil Mechanics and Geotechnical Engineering, Alexandria, Egipt, 5-9 October 2009, pp. 2777-2872.

15. Nelder J.A., MeAd R. (1965). A simplex method for function minimization. Computer Journal, 7(4), pp. 308-313.

16. Nogami Y., Murono Y., Morikawa H. (2012). Nonlinear hysteresis model taking into account $S$-shaped hysteresis loop and its standard parameters. The $15^{\text {th }}$ World Conference on Earthquake Engineering, Lisboa, Portugalia.

17. Peyrard, Сh. (2016), Offshore wind turbine foundations. Presentation of "Ecole tematique sur les technologies EMRs", 19-20 October 2016, Ecole Centrale de Nantes, France (https://formationemr16.sciencesconf.org).

18. SRokosz P.E., Dyка I., Bujкo M. (2017). Badania sztywności gruntu $w$ kolumnie rezonansowej. monograph, Wydawnictwo Uniwersytetu Warmińsko-Mazurskiego w Olsztynie. 
19. VArdanega, P.J., Bolton M.D. (2011), Practical methods to estimate the non-linear shear stiffness of clays and silts. Proc. 5th Int. Conf. on the Deformation Characteristics of Geomaterials, IOS Press, Amsterdam, Netherlands, pp. 372-379.

20. Yu Lu-Qing, WANG Li-Zhong, Guo Zhen (2015), Long-term dynamic behaviour of monopole supported offshore wind turbines in sand, Theretical and Applied Mechanics Letters, pp. 80-84.

21. Zaremba A. (2013), Modyfikacja podłoża gruntowego wświetle posadowienia turbin wiatrowych (cz. I), Geoinżynieria drogi mosty tunele, 45(4), pp. 42-48.

22. ZhaO J., BAO L., WANG G., (2017), Numerical analysis of soil settlement prediction and its application in large-scale marine reclamation artificial island project, Polish Maritime Research, Special Issue S3, 24(95), pp. 4-11.

23. Zhou M., Yuan W., Zhang Y., (2015), Seismic material properties of reinforced concrete and steel casing composite concrete in elevated pile-group foundation, Polish Maritime Research, Special Issue S1, 22(86), pp. 141-148.

24. Guideline for the Certification of Wind Turbines. Edition 2010, Germanischer Lloyd Industrial Services GmbH, Hamburg, Germany.

25. Rozporządzenie Ministra transportu, budownictwa i gospodarki morskiej z dnia 25 kwietnia 2012 r. w sprawie ustalania geotechnicznych warunków posadowienia obiektów budowlanych, Dziennik ustaw Rzeczypospolitej Polskiej.

26. Europe's onshore and offshore wind energy potential. An assessment of environmental and economic constraints. European Environment Agency, Technical report No 6/2009.

27. Deep Water. The next step for offshore wind energy. A report by European Wind Energy Agency, July 2013 (http://www. ewea.org)

28. Wind in power 2017. Annual combined onshore and offshore wind energy statistics. Wind Europe, February 2018, Brussels, Belgium (https://windeurope.org).

29. Offshore wind in Europe. Key trends and statistics 2017. Wind Europe, February 2018, Brussels, Belgium (https:// windeurope.org).

30. DIN 4178:2005-04, Glockentürme (Bell Towers), DIN Deutsches Institut für Normung e.V.

\section{CONTACT WITH THE AUTHORS}

\author{
Piotr Srokosz \\ e-mail:psrok@uwm.edu.pl \\ Ireneusz Dyka \\ e-mail:i.dyka@uwm.edu.pl
}

Marcin Bujko

e-mail:marcin.bujko@uwm.edu.pl

University of Warmia and Mazury

Heweliusza 4

10-724 Olsztyn

Poland 